\title{
Sputum induction in young cystic fibrosis patients
}

\author{
K. De Boeck, M. Alifier, S. Vandeputte
}

Sputum induction in young cystic fibrosis patients. K. De Boeck, M. Alifier, S. Vandeputte. (C) ERS Journals Ltd 2000.

ABSTRACT: A culture from the lower airway secretions is the optimal sample to guide antibiotic therapy in cystic fibrosis (CF) lung disease. The authors therefore examined whether sputum induction is an efficient, safe and acceptable procedure in CF children without spontaneous expectorations.

Nineteen patients were studied. Their mean age (range) was 8.6 yrs (4.3-15.2 yrs). Their mean forced expiratory volume in one second (FEV1) was $88 \%$ predicted (46$122 \%$ ). $\mathrm{NaCl}$ solutions from $0.9-6 \%$ were inhaled, after baseline lung function tests before and after salbutamol.

All patients did produce secretions. Alveolar macrophages were present in 16/19 induced samples. The procedure induced minor but significant bronchoconstriction: the mean change (range) in postsalbutamol FEV1 (\% pred) was -7 (-24-16). Percutaneous oxygen saturation remained above $90 \%$ in all children. The test had to be discontinued in one child because of cough and wheeze. Acceptability of the procedure evaluated using a visual analogue scale from $-7-7$ showed a mean value (range) at the final concentration of $\mathbf{- 1 . 2 3}(-\mathbf{6 . 1 6}-5.88)$.

It is concluded that sputum induction is possible, safe and acceptable in cystic fibrosis children who do not expectorate spontaneously.

Eur Respir J 2000; 16: 91-94.
Pediatric Pulmonology, Dept of Pediatrics, University of Leuven, Leuven, Belgium

Correspondence: K. De Boeck, Pediatric Pulmonology, Dept of Pediatrics, University Hospital Gasthuisberg, Herestraat 49, B-3000 Leuven, Belgium. Fax: 32 16343842

Keywords: Children

cystic fibrosis

lung disease

sputum induction

Received: October 251999

Accepted after revision April 32000
Chronic lower respiratory tract infection is the predominant manifestation of cystic fibrosis (CF). In young $\mathrm{CF}$ patients it is important to recognize and treat lung infection as early as possible, since with correct treatment Pseudomonas aeruginosa colonization can be avoided or delayed $[1,2]$. A culture from the lower airway secretions is necessary to guide antimicrobial therapy. Sputum cultures are considered a valuable substitute for a lower airway sample obtained by bronchoscopy or thoracotomy, since results from both sites will correspond in over $70 \%$ of cases [3].

Many young CF patients do not produce sputum. Since oropharyngeal cultures have only a poor positive predictive value $[4,5]$, bronchoalveolar lavage (BAL) remains the standard technique to obtain a lower airway sample in these patients. It is, however, an expensive, time consuming, unpleasant and potentially harmful procedure.

Recently, in patients infected with Pneumocystis carinii and Mycobacteria [6-8], sputum induction during hypertonic saline inhalation was proven to provide information comparable to that obtained by bronchoscopy and BAL. Similarly, cytological evaluation of induced sputum is considered helpful in patients with asthma and lung malignancies [9-11]. Sputum induction using hypertonic saline is efficacious in $>90 \%$ of adult asthmatics [12]. Although the drop in postsalbutamol forced expiratory volume in one second (FEV1) after inhalation was larger in asthmatics than in normals a fall exceeding $20 \%$ only occurred in $3 / 37$ patients. Sputum induction using hypertonic saline is also efficacious and safe in adolescent asthmatics $[13,14]$ and isotonic saline sputum induction appears to be safe in children with acute asthma [15]. Although the feasibility of sputum induction has been reported in patients with CF [16], a systematic study of sputum induction in young CF patients is lacking. Therefore, the current authors evaluated the efficacy, safety and the acceptability of sputum induction in CF children who do not expectorate spontaneously.

\section{Materials and methods}

\section{Patients}

Nineteen CF patients (10 males and nine females) who do not expectorate were studied. The diagnosis of $\mathrm{CF}$ was confirmed by a sweat chloride concentration $\geq 60 \mathrm{mmol} \cdot \mathrm{L}^{-1}$ [17] and/or genotyping. All patients were studied at least 14 days after a respiratory exacerbation. Their mean age was 8.6 yrs (SD 2.8; range 4.3-15.2), their mean height $130 \mathrm{~cm}$ (SD 17) and their mean weight $28 \mathrm{~kg}$ (SD 12). Bronchodilators were discontinued $12 \mathrm{~h}$ before the study; all remaining drugs and treatments were continued as prescribed. The parents gave informed consent and were present during the study. The study was approved by the University Hospital Gasthuisberg Ethics Committee.

\section{Study design}

First a nasopharyngeal aspirate was obtained. Baseline spirometry before and after a bronchodilator was obtained and chest auscultation, respiratory rate and percutaneous oxygen saturation $\left(\mathrm{Sa}_{\mathrm{a}} \mathrm{O}_{2}\right)$ were evaluated. Increasing $\mathrm{NaCl}$ 
concentrations (from $0.9-3 \%$ to $4.5-6 \%$ ) were inhaled through a mouthpiece during $5 \mathrm{~min}$ each. The children were encouraged to cough up sputum. Between inhalations a 5 min break was allowed to expectorate secretions and repeat chest auscultation, spirometry and pulse oximetry. After each concentration the acceptability of the procedure was evaluated by the child using a visual analogue scale (VAS) from -7 (very unpleasant) to 7 (very pleasant). The sputum induction was discontinued if the FEV1 fell by $>25 \%$ from the postbronchodilator value or if troublesome symptoms occurred (wheeze on auscultation, dry persistent cough, unacceptability claimed by child or drop in $\mathrm{Sa}_{\mathrm{a}} \mathrm{O}_{2}$ to $<90 \%$ ). The procedure was finished when sputum (scored by inspection) was produced or after inhalation of $6 \% \mathrm{NaCl}$.

\section{Methods}

Spirometry was performed using the Spirobank ${ }^{\mathrm{TM}}$ (Medical International Research, Italy) according to 1994 American Thoracic Society recommendations [18] both before and $15 \mathrm{~min}$ after inhalation of salbutamol $(4 \times 100 \mu \mathrm{g}$ Ventolin ${ }^{\mathrm{TM}}$; GlaxoWellcome, Brussels, Belgium, administered by metered dose inhaler and Volumatic ${ }^{\mathrm{TM}}$ (Glaxo Wellcome spacer). A bronchodilator was given to prevent bronchoconstriction [19]. Spirometric values are expressed as \% of predicted values according to QUANJER et al. [20].

$\mathrm{Sa}_{\mathrm{a}} \mathrm{O}_{2}$ was measured using the 504 Pulse Oximeter manufactured by Criticare Systems Inc. (Waukesha, WI, USA).

Twenty millilitres of each $\mathrm{NaCl}$ solution concentration was nebulized using an ultrasonic nebulizer (USV 82 Praxis; Medizinelektronik THOMÉ GmbH, Feinhauren, Germany) on the maximal settings. According to the manufacturer, under these conditions the nebulizer output is $\sim 4 \mathrm{~mL} \cdot \mathrm{min}^{-1}$ and the mass median aerodynamic diameter is $4 \mu \mathrm{m}$.

Part of the sputum sample was mounted on a slide and stained with Papanicolau solution. The presence of alveolar macrophages was assessed by light microscopy. Semiquantitative bacterial cultures were performed by innoculating the samples on MacConkey's agar, horse blood agar and chocolate agar. The samples were plated heavily on one third of the agar, in streaks over the next third of the agar and lightly on the remaining third. The samples were scored after $48 \mathrm{~h}: 0:<10$ colonies; $+:>10$ colonies but growth only on the first third of the agar; ++: growth on the first and the second thirds of the plate; +++: growth on the whole plate. The nasopharyngeal aspirates were streaked onto the same media and scored identically.

\section{Data analysis}

Since data distribution was normal, parametric statistics were used: t-test and repeated measurement analysis of variance (ANOVA) as indicated in the Results section.

\section{Results}

Spirometry could be reliably performed in all but two children, who were too young (4 and 6 yrs) to correctly perform the test. Baseline FEV1 (prebronchodilator) was $88 \%$ pred (SD 12), the mean per cent change postbronchodilator was $+2.5 \%$ pred (SD 8 ).
All 19 children did expectorate secretions. One child produced sputum after inhaling the $0.9 \% \mathrm{NaCl}$ solution, six children after $3 \% \mathrm{NaCl}$, one child after $4.5 \% \mathrm{NaCl}$, and 11 patients after inhaling $6 \% \mathrm{NaCl}$. At microscopic evaluation alveolar macrophages were present in 16/19 samples.

The majority of the children complained about the salty taste of the solution starting at $3 \% \mathrm{NaCl}$, but on the whole they assessed that the procedure was acceptable. Patients scored the hypertonic salt as significantly more unpleasant $(\mathrm{p}<0.0001$, paired t-test) compared to isotonic saline (fig. 1). Mean VAS value at the final saline concentration was $1.23(-6.16-5.88)$.

The mean breathing rate during the study did not change significantly $\left(22 \cdot \mathrm{min}^{-1}\right.$ at the start versus $23 \cdot \mathrm{min}^{-1}$ at the end of the procedure). Fourteen of the 19 children were coughing during or at the end of the study. Two of three children in whose samples macrophages were not found were also coughing during the study.

The mean change (range) in postsalbutamol FEV1 (\% pred) after the test was $-7 \%(-24-16 ; \mathrm{p}<0.03$; paired t-test; fig. 1). In six children the drop exceeded $10 \%$ in two children it exceeded $20 \%$. In one child (of 17 measured) a transient drop in FEV1 exceeding $10 \%$ occurred after inhaling isotonic saline and recurred after inhaling $4.5 \%$ saline. In four children (of 16 measured) the drop occurred after inhaling 3\%, in two (of 11 measured) after inhaling $4.5 \%$, and in one (of nine measured) after inhaling $6 \%$.

There was no significant drop in $\mathrm{Sa}_{\mathrm{a}} \mathrm{O}_{2}$ during the procedure (repeated measurement ANOVA). At the final inhalation mean $\mathrm{Sa}_{\mathrm{a}} \mathrm{O}_{2}$ was $96 \%$ (range: $92-98 \%$ ).

In one child wheeze was audible on auscultation and the test had to be discontinued because of a persistent dry cough and nausea. This child also had a 16\% drop in FEV1.

In one patient both culture specimens were lost, therefore final analysis includes 15 children. From the samples with alveolar macrophages present, $P$. aeruginosa was isolated in seven patients and Staphylococcus aureus in nine patients. Haemophilus influenzae was isolated in three patients. In eight patients no pathogen or just one pathogen was isolated (P. aeruginosa (2), S. aureus (4), H. influenzae (1), none (1)). P. aeruginosa had never been isolated before from the respiratory secretions of two patients. Concordance of bacteriological findings between nasopharyngeal aspirates and induced sputum is presented in table 1 .

\section{Discussion}

In this study the possibility of inducing sputum in young $\mathrm{CF}$ children who do not expectorate spontaneously has been demonstrated. It has been shown that sputum induction with hypertonic saline is acceptable and safe.

The mechanisms by which inhalation of hypertonic saline induce sputum production are not known. Possible modes of action are: attracting water into the airway by osmosis; improving viscoelastic properties of mucus, changing the spectroscopic structure of the mucus; or changing the ciliary beat frequency [21-23].

Hypertonic saline inhalation may induce bronchoconstriction [19], therefore bronchodilator pretreatment was given. Despite pretreatment, there was still a small but significant drop in FEV1 during the procedure; this drop exceeded $20 \%$ in two children. In six children FEV 1 was 
a)

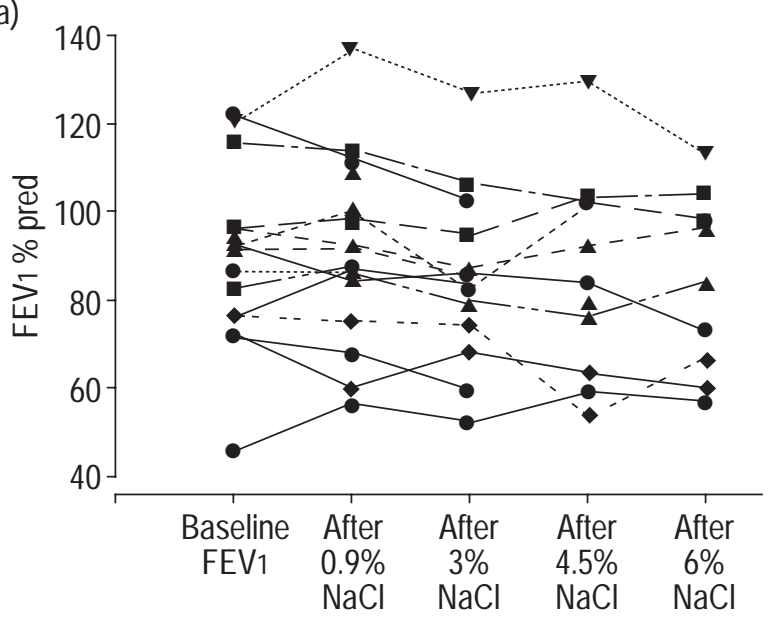

b)

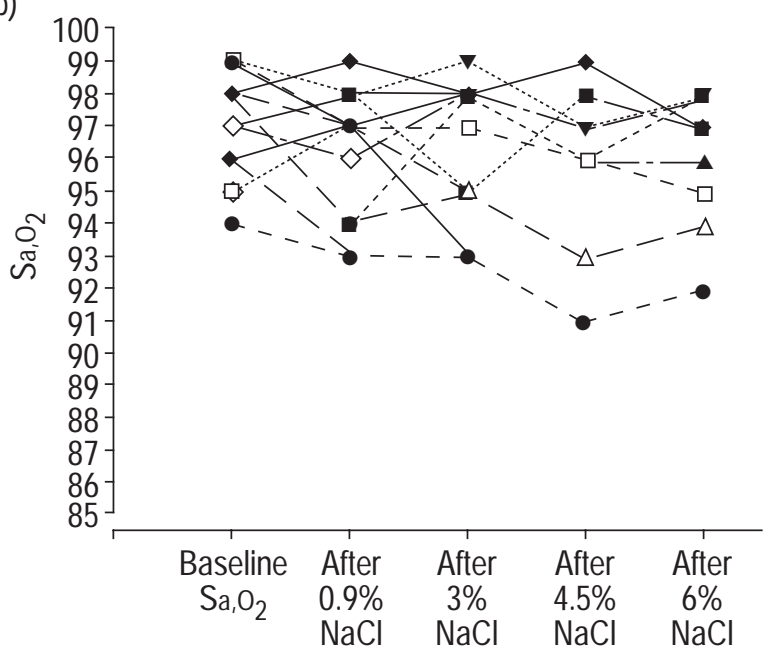

c)

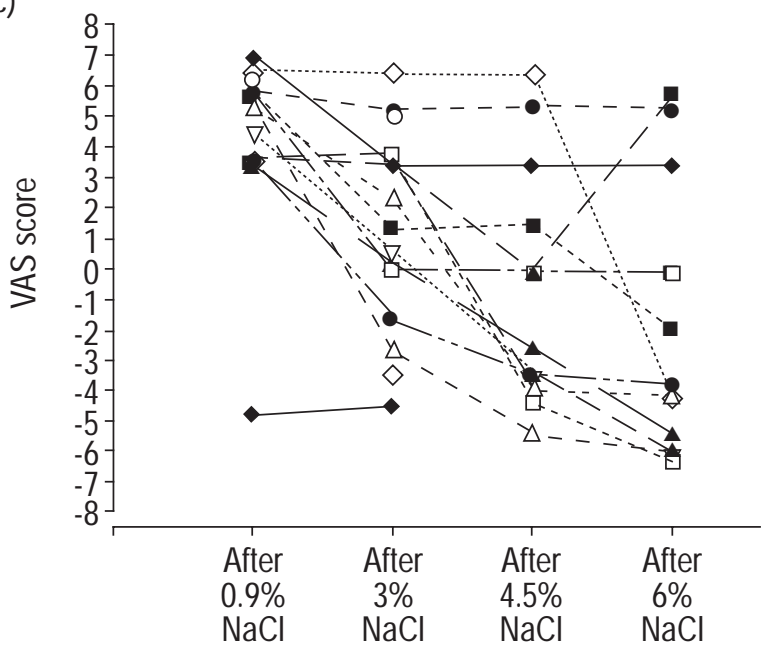

Fig. 1. - Change in forced expiratory volume in one second (FEV1); a) percutaneous oxygen saturation $\left.\left(\mathrm{Sa}_{\mathrm{a}} \mathrm{O}_{2}\right) ; \mathrm{b}\right)$ and acceptability expressed as visual analogue scale (VAS); c) during sputum induction. $\mathrm{NaCl}$ : sodium chloride. The different symbols represent individual patients.

improved at the final saline inhalation. This finding corresponds with the data of ENG et al. [24], showing a greater short-term lung function improvement in $\mathrm{CF}$ patients treated with hypertonic $(6 \%)$ compared to isotonic saline.
Table 1. - Concordance between culture results from nasopharyngeal aspirates and induced sputa

\begin{tabular}{lcc}
\hline & \multicolumn{2}{c}{ Induced sputum } \\
\cline { 2 - 3 } & Present & Absent \\
\hline $\begin{array}{l}\text { Staphylococcus aureau } \\
\text { Nasopharyngeal aspirate } \\
\text { present }\end{array}$ & 6 & 0 \\
$\begin{array}{l}\text { absent } \\
\text { Haemophilus influenzae }\end{array}$ & 3 & 6 \\
$\begin{array}{l}\text { nasopharyngeal aspirate } \\
\text { present }\end{array}$ & & \\
absent & 2 & 1 \\
$\begin{array}{l}\text { Pseudomonas aeruginosa } \\
\text { nasopharyngeal aspirate } \\
\text { present } \\
\text { absent }\end{array}$ & 1 & 11 \\
\hline
\end{tabular}

Sputum induction with hypertonic saline was more successful than with normal saline, but was also more unpleasant. (fig. 1). In the study protocol sequential administration of increasing concentrations of saline was used. Therefore the success of the higher concentrations of hypertonic saline could be due to the cumulative effect of four volumes of $20 \mathrm{~mL}$ rather than the increased concentration. The authors think that this is unlikely because after the official study period, they continued to perform sputum induction using only the 3 and $6 \%$ solutions. The initial results are confirmed: sputum induction is largely successful, about half of the children produce sputum after inhaling 3\% the rest only after inhaling 6\%. A drop in FEV $1>20 \%$ was uncommon and was never associated with hypoxaemia. A drop in FEV1 was as likely to occur after inhaling 3\% as it was after inhaling $6 \%$ saline.

Children were sometimes swallowing the secretions, especially the younger children. Special attention was required to coach the child to spit out all secretions.

In this study bacteriological cultures revealed the presence of $P$. aeruginosa in 7/15 of the patients. Nine out of 15 patients had $S$. aureus in the induced samples. In three out of 15 cases both pathogens were present. Cultures from a nasopharyngeal aspirate revealed the presence of $P$. aeruginosa in five patients, while $S$. aureus was present in six. The absence of the pathogen in the culture from the nasopharyngeal aspirate did not exclude the possibility that the pathogen occurred in the lower airways. This finding has also been observed by others [4]. However, the current authors found the ratio of negative Pseudomonas spp. cultures from the upper airways while positive from the lower to be higher than in studies mentioned previously $[4,5]$. The fact that a nasopharyngeal aspirate was evaluated whilst other studies have assessed an oropharyngeal swab may explain this difference.

In this study $P$. aeruginosa was cultured from induced samples in $5 / 10(50 \%)$ patients aged $<10 \mathrm{yrs}$. This is approximately the rate reported in the US Cystic Fibrosis Foundation Data Registry in 1995 (34\% at 5 yrs of age and $52 \%$ in $10 \mathrm{yr}$ olds); however, in the US database, it is not specified what sample is assessed. In the study of RosenFELD et al. [25] the Pseudomonas spp. carrier rate is 31\% at the age of 31-52 months.

Four out of five patients with $P$. aeruginosa isolated from nasopharyngeal aspirates had $P$. aeruginosa in the 
induced sputum as well. This finding corresponds with other data.

Bacterial colony densities (expressed semiquantitatively) were lower in nasopharyngeal aspirate than in induced sputum samples $(\mathrm{p}<0.03$ Chi-squared).

Further investigations are needed to compare sputum induction in $\mathrm{CF}$ patients with the standard techniques, such as BAL or protected brush samples. In three patients $P$. aeruginosa was isolated in induced sputum, this pathogen was also present in the lower airways in a subsequently performed BAL. Further studies comparing sputum induction specificity, sensitivity and predictive values with BAL or protected brush samples cultures are needed. This is especially important in view of the fact, that despite isolating the same pathogen from oropharyngeal and BAL specimens, the pathogens from different sites may be different strains [5].

In conclusion, sputum induction is successful, safe and acceptable in cystic fibrosis patients who do not expectorate spontaneously. It can be performed from the age of 4 yrs on.

\footnotetext{
Acknowledgements. The authors thank the children and parents participating in the study for their cooperation and patience. The authors also thank E. Verbeken and M. Drijkoningen for their assistance with cytological assessment.
}

\section{References}

1. Frederiksen B, Koch C, Hoiby N. Antibiotic treatment of initial colonisation with Pseudomonas aeruginosa postpones chronic infection and prevents deterioration of pulmonary function in cystic fibrosis. Pediatr Pulmonol 1997; 23: 330-335.

2. Valerius NH, Koch C, Hoiby N. Prevention of chronic Pseudomonas aeruginosa colonisation by early treatment. Lancet 1991; 338: 725-726.

3. Thomassen MJ, Klinger JD, Badger SJ, van Heeckeren DW, Stern RC. Cultures of thoracotomy specimens confirm usefulness of sputum cultures in cystic fibrosis. $J$ Pediatr 1984; 104: 352-356.

4. Ramsey BW, Wentz KR, Smith AL, et al. Predictive value of oropharyngeal cultures for identifying lower airway bacteria in cystic fibrosis patients. Am Rev Respir Dis 1991; 144: 331-337.

5. Armstrong DS, Grimwood K, Carlin JB, Carzino R, Olinsky A, Phelan PD. Bronchoalveolar lavage of oropharyngeal cultures to identify lower respiratory pathogens in infants with cystic fibrosis. Pediatr Pulmonol 1996; 21: 267-275.

6. Anderson C, Inhaber N, Menzies D. Comparison of sputum induction with fiberoptic bronchoscopy in the diag nosis of tuberculosis. Am J Respir Crit Care Med 1995; 152: $1570-1574$.

7. Foot AB, Caul EO, Roome AP, Oakhill A, Catterall JR. An assessment of sputum induction as an aid to diagnosis of respiratory infections in the immunocompromised child. J Infect 1992; 24: 49-54.

8. Bigby TD, Margolskee D, Curtis JL, et al. The usefulness of induced sputum in diagnosis of Pneumocystis carinit pneumonia in patients with the acquired immunodefi- ciency syndrome. Am Rev Respir Dis 1986; 133: 515518.

9. Fahy JV, Wong H, Liu J, Boushey HA. Comparison of samples collected by sputum induction and bronchoscopy from asthmatic and healthy subjects. Am J Respir Crit Care Med 1995; 152: 53-58.

10. Maestrelli P, Saetta M, Di Stefano A, et al. Comparison of leukocyte counts in sputum, bronchial biopsies, and bronchoalveolar lavage. Am J Respir Crit Care Med 1995; 152: $1926-1931$.

11. Khajotia RR, Mohn A, Schalleschak J, Vetter N. Induced sputum and cytological diagnosis of lung cancer. Lancet 1991; 338: 976-977.

12. Hunter CJ, Ward R, Woltmann G, Wardlaw AJ, Pavord ID. The safety and success rate of sputum induction using a low output ultrasonic nebuliser. Respir Med 1999; 93: 345-348.

13. Grootendorst DC, van den Bos JW, Romeijn JJ, et al. Induced sputum in adolescents with severe stable asthma. Safety and the relationship of cell counts and eosinophil cationic protein to clinical severity. Eur Repir J 1999; 13: 647-653.

14. Mattes J, Storm van's Gravesande K, Reining U, et al. NO in exhaled air is correlated with markers of eosinophilic airway inflammation in corticosteroid-dependent childhood asthma. Eur Respir J 1999; 13: 1391-1395.

15. Twaddell SH, Gibson PG, Carty K, Woolley KL, Henry RL. Assessment of airway inflammation in children with acute asthma during induced sputum. Eur Respir J 1996; 9: 2104-2108.

16. Henry RL, Gibson PG, Carty K, Cai Y, Francis JL. Airway inflammation after treatment with aerosolized deoxyribonuclease in cystic fibrosis. Pediatr Pulmonol 1998; 26: $97-100$

17. Gibson LE, Cooke RE. A test for concentration of electrolytes in sweat in cystic fibrosis of the pancreas utilizing pilocarpine by iontophoresis. Pediatrics 1959; 23: 697-700.

18. American Thoracic Society. Standardisation of spirometry. Am J Respir Crit Care Med 1994; 52: 1107-1136.

19. Popov TA, Pizzichini MM, Pizzichini E, Kolendowicz R, Punthakee Z. Some technical factors influencing the induction of sputum for cell analysis. Eur Respir J 1995; 8: $559-565$

20. Quanjer PH, Stocks J, Polgar G, Wise M, Karlberg J, Borsboom G. Compilation of reference values for lung function measurements in children. Eur Respir J 1989; 2: Suppl. 4, pp. 148s-261s.

21. Boucher RC. Human airway ion transport. Part one. Review. Am J Respir Crit Care Med 1994; 150: 271-281.

22. King M, Dasgupta B, Tomkiewicz RP, Brown NE. Rheology of cystic fibrosis sputum after in vitro treatment with hypertonic saline alone and in combination with recombinant hyman deoxyribonuclease I. Am J Respir Crit Care Med 1997; 156: 173-177.

23. Hogman M, Almirall J, Mork AC, et al. Nebulisation of hypertonic saline causes oedema of the airway wall. $J$ Submicrosc Cytol Pathol 1997; 29: 59-64.

24. Eng PA, Morton J, Douglass JA, Riedler J, Wilson J, Robertson CF. Short-term efficacy of ultrasonically nebulized hypertonic saline in cystic fibrosis. Pediatr Pulmonol 1996; 21: 77-83.

25. Rosenfeld M, Emerson J, Accurso F, et al. Diagnostic accuracy of oropharyngeal cultures relative to lower airway cultures in infants and young children with cystic fibrosis. Ped Pulmonol 1997; 24: Suppl. 14, A325. 